\title{
Grey relational analysis for Energy Storage Service Provider Influencing Factors
}

\author{
Qiang Wang ${ }^{1, \mathrm{a}}$, Jiaxin Wang ${ }^{2, \mathrm{~b}}$, Haiying Liu*3,c , Xin Liu ${ }^{4, \mathrm{~d}}$, Jiaoyu He $\mathrm{He}^{5, \mathrm{e}}$ \\ ${ }^{1}$ Affiliation: Department of Mechanical and Traffic Engineering, Ordos Institute of Technology, China \\ ${ }^{2}$ Affiliation: School of Finance and taxation, Inner Mongolia University of Finance and Economics Hohhot, China \\ ${ }^{3}$ Affiliation: Department of Management, Ordos Institute of Technology Ordos, China \\ ${ }^{4}$ Affiliation: School of Finance and taxation, Inner Mongolia University of Finance and Economics Hohhot, China \\ ${ }^{5}$ Affiliation: School of Finance and taxation, Inner Mongolia University of Finance and Economics Hohhot, China
}

\begin{abstract}
China faces the problems of abandoning wind and light and environmental pollution. Energy conservation and emission reduction as a new technology can effectively solve the above problems. In the process of building a Energy Storage Services project, the issue of Influencing Factors is the focus of attention. Aiming at the problem of Influencing Factors in Energy Storage Services systems, a Influencing Factors method based on gray correlation analysis is proposed. Adopting this method, one can avoid the influence of subjective factors on weight assignment through grey correlation analysis. Grey relational analysis can objectively analyze the proportion of each index in supplier's production consideration
\end{abstract}

\section{Introduction}

As China's economic development enters a new normal, there are problems such as low energy efficiency use of traditional energy and low level consumption of new energy. Simultaneously, there are problems such as smog and carbon emissions in environmental protection. Energy Storage Services system is a new technology that integrates new energy and traditional energy. By adopting a complementary energy supply mode between multiple energy sources, it can improve the efficiency of new energy utilization and alleviate the contradiction between energy supply and demand. Therefore, it is most important to choose the most suitable supply. Business becomes the focus of research on Energy Storage Services systems [1-3]. For the supplier's choice, we must establish a Energy Storage Services system evaluation index system; second, we should use the evaluation method to evaluate the candidate suppliers. The main contribution of this paper is to establish a set of Energy Storage Services system evaluation index system. In the evaluation process, in order to improve the objectivity of evaluation, the gray correlation degree method is used to calculate the weight, so as to avoid subjective evaluation.

Many researchers have devoted themselves to the issue of Influencing Factors. $\mathrm{Xu}$ et al.[4]provided considering the diversity of different equipment parameters and investment costs, a Influencing Factors method based on the Analytic Hierarchy Process (AHP) weight calculation method to obtain the Comprehensive Evaluation Index (CEI) is proposed.; Seyedmohsen and Kash [5] proposed a Influencing Factors method based on a Bayesian Network (BN) in considering the elasticity of Influencing Factors criteria; Under the background that multi-energy complementary systems are increasingly valued by governments and enterprises, there are few studies on Influencing Factors in the construction of multi-energy complementary systems in the existing literature.

From the perspective of Energy Storage Services system, this paper studies the optimal combination of wind, light, natural gas and energy storage equipment suppliers, and builds a Energy Storage Services system supplier evaluation index system. At the same time, in order to avoid the subjectivity of the evaluator, choose grey relational analysis. At last, The grey theory evaluate Energy Storage Services system vendors and to illustrate and validate them through specific examples.

\section{Grey Relational Analysis for Selection of Evaluation Index and Determination of Weight}

\subsection{Grey Relational Analysis}

Let the observation data $x_{i}(k)(k=1,2, \ldots, n)$ is the vector for the evaluation index. [10] The steps of the gray correlation analysis method are as follows:

1) Let the reference vector is:

$$
X_{0}=\left\{x_{0}(1), x_{0}(2), \ldots, x_{0}(m)\right\}
$$

2) The vector being compared is:

$$
X_{i}=\left\{x_{i}(1), x_{i}(2), \ldots, x_{i}(m)\right\}, \quad i=1,2, \cdots, n
$$

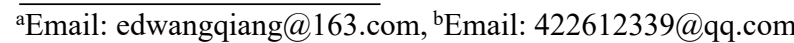

cEmail: lhy liuhaiying@163.com,*Correspondence: lhy liuhaiying@163.com, Tel.: +86-186-8623-7979/0477-8591194

dEmail: 3092076139@qq.com, ${ }^{\mathrm{e} E m a i l: 3544378722 @ q q . c o m}$ 
3) The correlation coefficient between each comparison vector and the reference vector can be calculated according to following equation:

$$
\eta_{i}(k)=\frac{\min _{s} \min _{t}\left|x_{0}(t)-x_{s}(t)\right|+\rho \max _{s} \max _{t}\left|x_{0}(t)-x_{s}(t)\right|}{\left|x_{0}(k)-x_{i}(k)\right|+\rho \max _{s} \max _{t}\left|x_{0}(t)-x_{s}(t)\right|}
$$

Where $\min _{s} \min _{t}\left|x_{0}(t)-x_{s}(t)\right|$ is the minimum difference of two levels, $\max _{s} \max _{t}\left|x_{0}(t)-x_{s}(t)\right|$ is the maximum difference of two levels, $\rho \in[0,1]$ is the resolution coefficient. As $\rho$ increases, the resolution increases, the more commonly used $\rho=0.5$.

4) Average correlation coefficient can be calculated according to following equation:

$$
r_{i}=\frac{1}{n} \sum_{k=1}^{n} \eta_{i}(k)
$$

5) Based on the average correlation coefficient, the evaluation results are obtained.

6) Vector $r=\left(r_{1}, r_{2}, \ldots, r_{n}\right)$ can be normalized according to following equation:

$$
w_{i}=\frac{r_{i}}{\sum_{k=1}^{n} r_{i}(k)}
$$

The weight vector for each indicator is:

$$
W=\left(w_{1}, w_{2}, \ldots, w_{n}\right)
$$

\subsection{Evaluation Index Selection}

In order to enable the selected suppliers to meet the requirements of Energy Storage Services systems, this paper builds a Energy Storage Services system supply based on the literature [6-7], through expert consultation and Energy Storage Services integration optimization demonstration project field research. The evaluation index system is shown in Figure 1. The evaluation index system includes price indicators, time indicators and quality indicators. These indicators are both cost-effective and cost-based. Through the evaluation index system, the Energy Storage Services system supplier can be evaluated objectively and accurately, so that the best supplier combination can be selected.

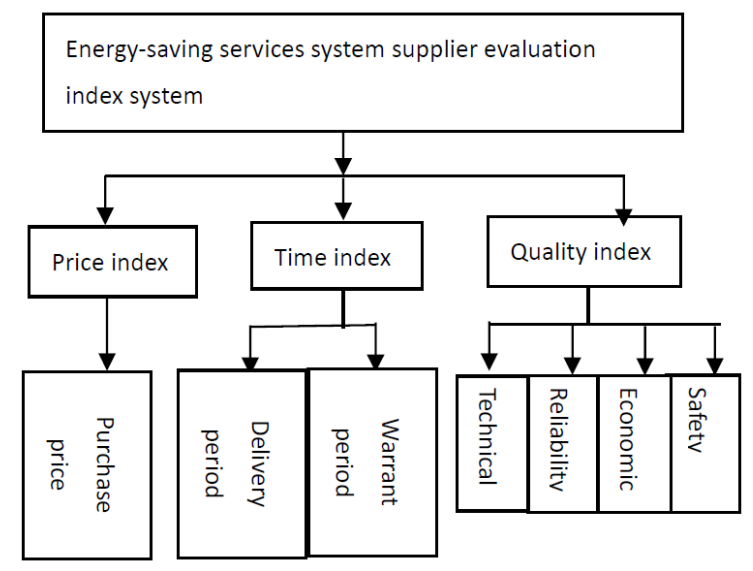

Fig 1. valuation Index System for Multi-energy Complementary Systems

\section{Experiment and analysis}

\subsection{Simulation environment}

In order to verify the effectiveness of the Energy Storage Services system Influencing Factors method, Matlab 2014 b was selected for simulation on Intel Pentium 2.90 GHz CPU, 4GB RAM, 64-bit Windows 10 Professional operating system. The simulation steps are as follows: First, data normalization; Second, using gray correlation analysis to determine the weight;

Taking a Energy Storage Services project in Inner Mongolia Autonomous Region as an example, The main parameters of project procurement are shown in Table 1

\subsection{Data normalization}

As can be seen from Table 1, many of the evaluation indicators are of different dimensions and need to be normalized. $X=\left\{X_{1}, X_{2}, \ldots, X_{N}\right\}$ and $Y=\left\{Y_{1}, Y_{2}, \ldots, Y_{N}\right\}$ represent raw data and normalized data, respectively.

For cost-type indicators, that is, when the evaluation value decreases as the index increases, the formula is used:

$$
Y=\frac{X_{\max }-X_{i}}{X_{\max }-X_{\min }}
$$

For the benefit indicator, that is, when the evaluation value increases as the index increases, the formula is used

$$
Y=\frac{X_{i}-X_{\min }}{X_{\max }-X_{\min }}
$$

Where $X_{\max }$ and $X_{\min }$ represents the minimum and maximum values, respectively.

In the evaluation index, the purchase price and delivery period are cost-type indicators, using formula (7), and the remaining indicators are benefit-type indicators. Using formula (8), It can be seen from Table 2 that weighted quantification of time and quality indicators yields two composite indicators the values of all the evaluation indicators are in the $(0,1)$ range, and each indicator achieves dimension lessness, which is convenient for comprehensive evaluation. 
Table1. Energy Storage Services system supplier parameters

\begin{tabular}{|c|c|c|c|c|c|c|c|c|}
\hline \multirow[b]{2}{*}{ Type } & \multirow[b]{2}{*}{ Supplier } & \multirow{2}{*}{$\begin{array}{l}\text { Price index } \\
\text { Purchase } \\
\text { price } \\
/ 10^{4} \text { Yuan }\end{array}$} & \multicolumn{2}{|l|}{ Time index } & \multicolumn{4}{|c|}{ Quality index } \\
\hline & & & $\begin{array}{l}\text { Delivery } \\
\text { period } \\
\text { /Days }\end{array}$ & $\begin{array}{l}\text { Warrant } \\
\text { period } \\
\text { /years }\end{array}$ & $\begin{array}{l}\text { Technical } \\
/ \%\end{array}$ & $\begin{array}{l}\text { Reliability } \\
/ \%\end{array}$ & $\begin{array}{l}\text { Economic } \\
/ \%\end{array}$ & $\begin{array}{l}\text { Safety } \\
/ \%\end{array}$ \\
\hline \multirow{3}{*}{ Wind } & $\mathrm{A}_{2}$ & 7 & 48 & 1 & 83 & 83 & 87 & 85 \\
\hline & $\mathrm{A}_{3}$ & 5 & 29 & 2 & 81 & 86 & 83 & 81 \\
\hline & $\mathrm{A}_{4}$ & 8 & 57 & 2 & 92 & 94 & 90 & 86 \\
\hline \multirow{5}{*}{ Photovoltaic } & $\mathrm{B}_{1}$ & 8 & 28 & 2 & 86 & 85 & 79 & 84 \\
\hline & $\mathrm{B}_{2}$ & 7 & 14 & 1 & 84 & 84 & 89 & 88 \\
\hline & $\mathrm{B}_{3}$ & 6 & 16 & 2 & 83 & 90 & 84 & 84 \\
\hline & $\mathrm{B}_{4}$ & 3 & 10 & 1 & 95 & 97 & 94 & 89 \\
\hline & $\mathrm{B}_{5}$ & 5 & 38 & 3 & 89 & 96 & 90 & 91 \\
\hline Natural gas & $\mathrm{C}_{1}$ & 19 & 17 & 2 & 87 & 87 & 80 & 85 \\
\hline
\end{tabular}

Table2. Normalized data of Energy Storage Services system supplier parameters

\begin{tabular}{|c|c|c|c|c|}
\hline Type & Supplier & $\begin{array}{l}\text { Price } \\
\text { index }\end{array}$ & $\begin{array}{l}\text { Time } \\
\text { index }\end{array}$ & $\begin{array}{l}\text { Quality } \\
\text { index }\end{array}$ \\
\hline \multirow{5}{*}{ Wind } & $A_{1}$ & 0.8846 & 0.0000 & 0.0313 \\
\hline & $\mathrm{A}_{2}$ & 0.8462 & 0.2317 & 0.2545 \\
\hline & $\mathrm{A}_{3}$ & 0.9231 & 0.4726 & 0.1204 \\
\hline & $\mathrm{A}_{4}$ & 0.8077 & 0.3018 & 0.6339 \\
\hline & $\mathrm{A}_{5}$ & 0.7692 & 0.4177 & 0.4500 \\
\hline \multirow{5}{*}{ Photovoltaic } & $\mathrm{B}_{1}$ & 0.8077 & 0.4787 & 0.1923 \\
\hline & $\mathrm{B}_{2}$ & 0.8462 & 0.4390 & 0.3834 \\
\hline & $\mathrm{B}_{3}$ & 0.8846 & 0.5518 & 0.2970 \\
\hline & $\mathrm{B}_{4}$ & 1.0000 & 0.4634 & 0.8546 \\
\hline & $\mathrm{B}_{5}$ & 0.9231 & 0.5427 & 0.7319 \\
\hline \multirow{3}{*}{ Natural gas } & $\mathrm{C}_{1}$ & 0.3846 & 0.5457 & 0.2766 \\
\hline & $\mathrm{C}_{2}$ & 0.1923 & 0.5884 & 0.5440 \\
\hline & $\mathrm{C}_{3}$ & 0.0000 & 0.6951 & 0.4108 \\
\hline \multirow{2}{*}{$\begin{array}{l}\text { Energy storage } \\
\text { equipment }\end{array}$} & $\mathrm{D}_{1}$ & 0.8077 & 0.9390 & 0.9545 \\
\hline & $\mathrm{D}_{2}$ & 0.9231 & 0.8750 & 0.7996 \\
\hline
\end{tabular}

\section{Results and analysis}

The gray correlation analysis obtains the weight values of price index, time index and quality index $w_{1}=0.39$, $w_{2}=0.31, w_{3}=0.30$. Therefore, its objective function is: $\max f(x)=0.39 C+0.31 T+0.30 Q$

\section{Conclusion}

In order to select the best supplier combination from a large number of Energy Storage Services system suppliers, the paper draws the following conclusions:

(1) Through the evaluation index system, it can provide basic support for Influencing Factors of Energy Storage Services systems.
(2) In order to avoid the influence of subjective factors on the weight assignment process, a Influencing Factors method based on gray correlation analysis.

(3) The results show that supplier $\left(A_{3}, B_{4}, C_{2}, D_{1}\right)$ for Energy Storage Services systems can provide the best product mix. The experimental results demonstrate the feasibility and rationality of the proposed method.

In the research process of this paper, there are some shortcomings. First, the indicators considered in this paper are relatively few. In the future research process, evaluation indicators need to be re-defined for different Energy Storage Services projects. An evaluation system that adapts to a wider situation. Second the evaluation method used in this paper is gray correlation analysis, and future considerations, combined with new heuristic algorithms, further expand the research. 


\section{Conflicts of Interest}

The authors declare that there are no conflicts of interest regarding the publication of this paper.

\section{Acknowledgments}

This work was supported by Research Program of Science and Technology at Universities of Inner Mongolia Autonomous Region(NJSY19262); Natural Science Foundation of Inner Mongolia Autonomous Region of China (2019MS07005,2019MS07006); "Young Talents in Science and Technology" in Higher Education Institutions in Inner Mongolia Autonomous Region of China(NJYT20-A19); Innovative talent team project for ecological restoration and high-quality development of cultural tourism industry in Ordos; Talent Development Fund Project in Inner Mongolia Autonomous Region of China([2019]114); Inner Mongolia Social Science Foundation Project （20B64）.

\section{References}

1. K. Qu, T. Yu, L. Huang,et al. "Decentralized optimal multi-energy flow of large-scale integrated energy systems in a carbon trading market,". Energy, no. 149,pp. 779-791,2017.

2. W. Wang, W. Xang, H. Jia, et al. Economic Dispatch of Generalized Multi-source Energy Storage in Regional Integrated Energy Systems [J]. Energy Procedi, 2017,142: 3270-3275.

3. X. Liu, Y. Liu, Y. Zhou, et al. Integrated Analysis and Planning of Energy Conversion and Storage Devices in Multi-vector Energy Systems [J]. Energy Procedi, 2017,142: 2015-2020.

4. Q. S. Xu, M. J. Xu, G. D. Li, et al. Configuration optimization model of multi-energy distributed generation system [J]. Journal of Southeast University(English Edition),2017,33(2): 182-188.

5. H. Seyedmohsen, B. Kash.

A Bayesian network model for resiliencebased Influencing Factors [J]. International Journal of Production Economics,2016,180(2): 68-87.

6. C. S. Xue, D. P. Dong, K. Y. Duan, et al. Coordination Degree Evaluation of Low Carbon Generation Expansion and Grid Planning Based on Analytic Hierarchy Process Method and Distance Coordination Degree [J]. Power System Technology, 2011,36 (11): 1-6.)

7. E. X. Zhou, F. T. Li, H. Zhu. Cost-benefit Evaluation of Microgrid Based on Analytic Hierarchy Process [J]. Electric Power Construction, ,2013,34 (3): 1-6.) 